\title{
Manus Operandi: Film, Sculpture, Choreography
}

Elinor Cleghorn

I maintain that before the invention of the moving-picture no one knew

before the possibilities latent in a foot-a hand-a hat.'

Fernand Léger

This paper is partially inspired by the discovery of Richard Serra's 1968 film Hand Catching Lead, which is in the digital archive component of the Hayward Gallery's recent exhibition, "Move: Choreographing You." The archive, co-curated by André Lepecki, is comprised of over 120 visual texts embedded within a navigational portal, resembling a mobius strip that invites the viewer-user to choreograph their own smooth movement through a related history of dance and visual art over the last five decades. Seminal performances, dances and events are documented alongside videos, still photographs, and several films. The inclusion of Serra's first film, a single-shot, three-minute depiction of a hand engaged in a repetitious attempt to catch small pieces of lead falling into the frame from somewhere unseen, struck me because of its staging of the hand - the manus - as the instrument of an inherently choreographic action. Musing on the significance of the inclusion of this anti-illusionist game of catch in an archive attempting to re-present a recent history of the appropriation, disruption, expansion, and contraction of dance movement and choreographic configurations within and by visual art practices, I began to consider the ways this simple gesture, this blunt action, constitutes a form of dance, or how it might be approached, perhaps, as screendance. More particularly, my thoughts turned to the specificity of the commitment of this pragmatic performance of dumb effort to the material permanence of $16 \mathrm{~mm}$. Serra, of course, was a sculptor, and Hand Catching Lead —along with Hands Scraping, also made in 1968 -implies an attempt to filmically describe the making body's relation with manipulative material within a medium that requires a labour of mechanistic and physical manipulation in the service of the creation of an essentially formless projected image. This relation, which on both sides implies a passage from active, muscular engagement to physical estrangement, is played out in Serra's film as a frustrated, minimal dance between animate limb and inanimate material.

My thoughts turned to another film featuring bodily movement and gesture modulated according to the presence of sculptural objects: Maya Deren's incomplete project, Witch's Cradle, made in 1943. It exists as a series of outtakes featuring various interactions with string, which is proposed as that of which Marcel Duchamp's web-like interventionist string sculptures of the early 1940s were spun. Sequences of footage of Duchamp himself, and Chilean Surrealist painter Roberto Matta, engaging with tenacious, enigmatic forms of string, are juxtaposed with scenes filmed at the Surrealist gallery of Peggy Guggenheim's "Art of This Century" museum. Viewing the existing fragments of Witch's Cradle conveys 
the sense-even in this embryonic form - that Deren intended the scenes to unfold on screen according to an intensely rhythmic, strategically choreographed pattern of edits. Broadly speaking, these two films share in common the relation of the body and sculptural forms. More particularly, both consist of staged performances for camera of an encounter between the artists and the material of their manipulation. The activity of the hand, in both films, is centralised as instigating, negotiating the initial "terms" of the making body's productive enmeshment with the materials in question. And both, crucially, confer a ludic dimension upon this performance of body/form parity, to divergent ends. Where Hand Catching Lead configures the initialising moment of tactile attempt underscoring sculptural productive labour as a simple game of aimless catch, Witch's Cradle stages a series of encounters between bodies and sculptural forms in which the "subject" appears implicated in some unfathomable puzzle. In this paper I explore the significance of filmic choreographics in rendering a cinematically specific vision of the relationship between body and manipulative materials. Through Serra's Hand Catching Lead and Deren's Witch's Cradle, I will describe the filmic medium as uniquely capable of visually conjuring the space between sculptural object and active subject as reactive, vital, and animatedly responsive. ${ }^{2}$ In addition, I will discuss Daria Martin's In the Palace, a film made in 2000, which takes its title from Alberto Giacometti's 1932 diminutive sculptural scaffold The Palace at 4am, as a cinematically specific expansion of a compressed form of sculptural space.

\section{Enclose and release: Richard Serra's Hand Catching Lead}

Richard Serra made his first film, Hand Catching Lead, in 1968. This three-minute film of a hand engaged in the repetitious attempt to catch pieces of falling metal, attends focus entirely upon the hand and forearm which, in the visible absence of the rest of the body, "perform the totality of the action." ${ }^{3}$ The film presents a durational vision of a muscular act with no discernible ambition save for the momentary and occasionally achieved catch that affords the briefest contact of flesh enclosed about metal. Almost as soon as the object is caught, it is released to fall through the frame. Other metal pieces defy such enclosure and the hand haplessly grasps, too late. For Rosalind Krauss, in Passages in Modern Sculpture, the film is "composed entirely of those catches and misses, that-and the sense of the visually disembodied hand's intense concentration on the deed."

Hand Catching Lead stages a thwarted, nominal dance between body and material, inevitability and intervention, effort and occasion. Despite its "disembodied" appearance, there is a sense of full-bodied occupation concentrated within the sinew and muscle of the visually isolated limb. It trembles, shakes; its moves appear interpretative, clumsily intuitive. The metal pieces bear out the inevitability of their weight, of their material property, which contrasts with the apparent conscious behaviour of the hand. Occasionally, the throwing of another metal sheet is beckoned with a "come on" twitch of the fingers. Benjamin Buchloh, in his essay Richard Serra's Early Work: Sculpture between Labour and Spectacle, Hand Catching Lead, distils into repetitious and clownish activity the universal conditions of bodies condemned to perform the laborious processes of industrial production. This is the hand, argues Buchloh, "of a subjected subject, reduced to the most minute and infinite acts of pointless and fragmented repetition." 
I propose that Hand Catching Lead offers itself to another viewing-reading, one that does not deny the anti-heroic laborious performance Buchloh registers, but that, in accompaniment, considers the way the film mimes the body's frustrated strive towards a tactility of engagement with objects, matter, or solid forms. The film stages the invisible body and the present hand and arm as posed in readiness for contact with the lead pieces. The viewer, in turn, anticipates the simple rhythmic stresses of the hand opening and either slapping its own skin or interrupting the object's course of fall. Through a choreographic reduction of the profound labour of sculptural process to quotidian gesture, Hand Catching Lead brings to mind an imagining of the ways in which manipulative matter - in this case, lead — at once evades and invites tactility. Sheet lead, in the proportions featured in the film, is at once soft and resistant: its essential malleability is visible on screen, as the pieces caught in the hand appear slightly scrunched once released to fall. Lead made molten, on the other hand, is viscous potential: it requires an activity of the body, a precisely productive gesture, to bring it into form before it solidifies, before it inevitably shifts into resistance. For Krauss, the act of gestural repetition "performed" in Hand Catching Lead is a demonstration of an "almost absurd tenacity" of endeavour she observes as consistent with Serra's sculptural processes at the time of the film's making. ${ }^{6}$ She describes how Casting (1969) was formed in the act of flinging molten lead into the angle between the floor and the wall, before "pulling away the hardened shape into the center of the room, repeating the gesture, and thereby building a succession of lead strips, as sequential and near alike as waves following one another toward the shore." ${ }^{\prime \prime}$ The fundamentals of Serra's practice around the late 1960s were defined by such active bodily engagement, whereby the work was produced through a particular rubric of physical investment governed and determined by the properties peculiar to the sculptural material. In Hand Catching Lead, the hand is cast as blunt instrument. The game of blind-catch reasserts that initial moment of inelegant, stumbling contact between body and material that is not yet productive, not yet artistically determinative.

Hand Catching Lead consists of the filmed performance of a simple, playful engagement between limb and material wherein two currents of movement, defined by that of the hand action and that of the material's trajectory, occasionally converge in rhythmic contact. Its inclusion in the Move archive suggests that we are to receive and interpret this spare, anti-illusionist game of chance played out for camera as a form of dance. The limb moves about the screen in anticipation of the catch; it adjusts its position in accordance with the assumed proximity of the falling object; it dances a course upon which choreographic governance alternates between object and hand, between capture and release. The work illustrates something of the filmic medium's capacity to confer a dance-like quality upon engagements between animate bodies and inanimate objects. If we imagine the pieces of lead as constantly trying to outdo the determination of the hand, we might consider that the film plays upon cinema's facility to imbue objects with a lively, animated sense of object life. Rachel Moore, in Savage Theory: Cinema as Modern Magic, writes of the cinematic treatment of objects as inferring upon them a transformative quality, as shifting them, through a magical reinstatement as image, into vitality. Through Jean Epstein's essay "On Certain Characteristics of Photogenie," which first appeared in text in 1924 after being given in various incarnations as a lecture in 1923, Moore suggests that objects, through what she describes as "the eminently unreal realm of cinema," open themselves up to an animistic understanding: "(objects) burn bright as constellations of meaning and crackle 
with tactile effects; things take on life." It is precisely in the act of being caught that the falling metal in Serra's film-despite the emphasis, through single shot, on the metal's inevitable objective trajectory-becomes a mischievous dance partner to the hand, which in turn appears to take on a quality of objectnes, somehowmore instrumental than bodily This brings to mind Kenneth Gross's discussion, in his 2009 essay The Madness of Puppets, the scene from Charlie Chaplin's The Gold Rush, in which an oneiric transformative force, transposed onto a bread roll with two forks stuck into it, conjures the image of everyday objects moving, as puppets might, with "ballet like grace."10 Through its focus on the hand as the implement of action, Hand Catching Lead choreographically inscribes metal as subject to the slightest transformative force. The hand is configured as the instrumental transmitter of what Gross describes as "animating impulse."11

\section{Hand-Eye Conundrums: Maya Deren's Witch's Cradle}

Maya Deren's Witch's Cradle-available to view as a series of outtakes as part of Martina Kudlácek's 2001 documentary, In the Mirror of Maya Deren —was made in 1943, and never completed. It features footage filmed at Peggy Guggenheim's "Art of This Century" gallery juxtaposed with scenes of painter Roberto Matta being crept upon by a length of string, and others of Marcel Duchamp attempting to puzzle the material into strategic order through the playing of the finger lacing game Cat's Cradle. Requiring of the hand a sustained yet delicate grasp of string, Cat's Cradle imposes upon the fingers a minute choreography of instrumental movement. Maureen Turim, in her essay The Ethics of Form: Structure and Gender in Maya Deren's Challenge to Cinema, describes this "game of geometric transformations of a string loop whose rule is not to disturb the hidden order of the lacing as one passes the loop from player to player" as metaphorically structuring Deren's intriguing film. ${ }^{12}$ In the outtakes we see footage of Matta, hounded, haunted, by a tenacious, ominous length of string as it moves across his shoulders. In another scene, the length winds round his neck and pulls his head backward in the mock-mime of a hanging. The string, moved through by actress Anne Matta Clark, Roberto Matta's then wife, seems to symbolically coordinate the geographically estranged yet symbolically coincident spaces occupied by Duchamp and Matta. Duchamp and Matta's tangles with the strangely vital material are juxtaposed with cuts featuring Clark encountering sculptural objects in the Surrealist gallery of "Art of This Century." The objects appear, through Deren's camerawork and the use of trick techniques, imbued with a conspiratorial animism. The string appears to hound Clark, too, as it gradually laces up her arm in one scene, visible as a precluding, unfathomable string sculpture in another, or pulled taut, patterned through her fingers, in one of the film's most arresting fragments. There is a strong sense that Deren intended the film to be structured in accordance with a rigorous yet determinably puzzling logic. Scenes are repeated, glances and poses shot from multiple angles are juxtaposed in dynamic edited sequences, still poses and isolated hand actions are cut against perambulatory impressions of sculptural space. Witch's Cradle illustrates Deren's concern to simultaneously transpose and counteract the overwhelming sense of unhinging strangeness imposed upon the viewing subject in affective receipt of the Surrealist art object. As Clark's encounters with the objects and forms suggest a gathering unravelling of a sense of "self," Deren's edits and cuts become more rhythmically strategic, more consciously choreographic in structure. For 
Turim, in her discussion of Deren's use of childhood games as the very basis for organising filmic sequences, such structural reference to forms of play, which imply an innocent yet deeply invested ritualised activity, "become [Deren's] way of linking the modern audience to the ritual participation in art she seeks as antidote to a modernity hollow of meaningful ritual."13

Deren's use of game as a symbolic configuration, as a device in establishing the form of encounter between individual subjects and subjects and space, is a key facet of her "choreocinematic" conceit. In an article published in Film Culture in 1965, Deren proclaims her regard for children's games as the "ultimate in original, secular ritual." She writes:

Often they [games] are created by the players themselves, but even when they are "learned," the tradition is not so much an inviolable authority for the form as it is a suggestion which may be modified, elaborated, combined with others, etc. What is important is that while the tradition is easily violable, the form, once established in its immediate terms, is as rigidly executed as if it had an exterior, traditional obligation. ${ }^{14}$

Such conception of film as a specially integrated form-as, in Deren's words, a "controlled manipulation" defined not by the nature of its content but by the concept of its methodwas for Deren absolutely intrinsic to her conjuring of "film dance or dance on film."15 In her writings on Ritual in Transfigured Time, a film completed in 1946 in which the movements of guests at a cocktail party become a choreographic configuration from which a dance duet between Frank Westbrook and Rita Christiani extends, Deren identifies the film as operating according to a unifying choreographic concept, wherein all constituent movements, "stylised or casual, full-figured or detailed-are related to each other, both immediately and over the film as a whole."16 The game of "statues" played out in Ritual in Transfigured Time integrates dance action and physical play across a choreographic stratum. The players swing each other by the hand before letting go, twirling away with the force of the spin until their movement is arrested "in a poignant still pose, an action sculpture that bears the trace of the spin."17 Deren's inferring of a dance-like quality upon the movement and action of her screen bodies is characteristic of what I describe as a visible instance of technological enmeshment, whereby the facility of filmic technique to, for example, freeze the body in statue pose, calls the viewer forth to attend to the cinematic specificity of the occasion of movement or gesture. Often in Deren's films this occurs to embellish or extend the physical, "human," appearance or limits of movement performed for the camera. In A Study in Choreography for Camera, Talley Beattey's now iconic sustained leap was achieved through the use of multiple camera angles applied to the capturing of his ascent and descent, cut across several frames. Crucial to Deren's composition of what she described as this "idealised, floating leap" was the transcendence of the gravitational logics of bodily movement, achieved through cinema's technological facility in proposing an elastic expansion of temporality. ${ }^{18}$ Beattey's muscular initiation of the movement, committed to camera, becomes a sustained impossibility on screen through the edited juxtaposition of photographed stages of originating movement. If children's games for Deren constituted the opportunity for collaboration, modification and elaboration of action within an enclosure of formal constraints, then in her conjuring of dance for film or filmic dance, the body's muscular logic can be approached as a strategic constraint, a given form that offered itself 
up to transcendence through cinematic means. In A Study in Choreography for Camera, dance becomes a strategy for Deren's filmic conjuring of the imagined, latent potential enclosed within the modern body. In turn, the dancing screen body is configured as the very site for the demonstration, as Deren describes, of the active potential of "techniques peculiar to the motion picture camera."19

In Witch's Cradle, the material string functions as a conceptual strategic motif, binding three disparate players in a game the rules of which are unclear. It seems to function as a symbolic object, "passing" from player to player as it creeps across scenes or locations, unravelling or tightening in various formal configurations. Deren's utilisation of string as a filmic device is particularly intriguing. It appears in some scenes as an uncannily animate object, apparently moving autonomously and capable of some silent violence. In others, it takes sculptural form, impeding Clark's movement around the gallery space or subverting the appearance of proximal art objects. Whilst the fragmented outtakes of Witch's Cradle were never reconciled into a completed filmic complex, nonetheless the sense is one of Deren intending the work to cinematically extend the affective force of Duchamp's spatially interventionist string sculptures. In 1942, Duchamp was asked by André Breton to oversee the installation of the retrospective "First Papers of Surrealism" at New York's Whitlaw Reid Museum. The show had a scarce budget, and paintings were hung unsatisfactorily on rows of temporary screens. Krzysztof Fijalkowski, in his essay Marcel Duchamp, Surrealist Exhibitions and Restless Space, writes of Duchamp's solution, which involved the winding of one mile of string around the room, over, above and between the exhibits. The installation operated to disrupt and destabilise the proposed and expected relation of viewer and artwork, whilst, to follow Fijalkowski, simultaneously opening up a nexus of uncanny visual opportunities:

Duchamp's intervention effectively hamstrung the conventions of visiting, moving around and viewing the gallery and its contents, unravelling and fracturing the very act of looking that artworks purported to invite. At a stroke, space could become inviable in normal mode, yet strangely visible, where twine could articulate hidden vectors of relationships and meanings, the migrations of the eye finding "invisible" space, the negative gaps between objects and subjects now seeming activated and in tension. ${ }^{20}$

One might imagine that Deren, in the making of Witch's Cradle, took as her point of departure the occlusive, membrane-like functionality of the string in sculptural form. String, as sculptural material installed about the totality of a room, has the capacity to dismantle the feasibility of movement around a given space. In its form as open textile sculpturenot solid but somehow peculiarly arterial -it invites a complete visual re-appropriation of that space's assumed modality: it forces one to look again from a physically preclusive vantage point. Deren attempted to cinematically transpose the sense of spatial subversion effected by the installation of this web of string by staging the "negative gaps" between viewing subject and gallery objects as precisely "activated and in tension." And that sense of activation, of tension, instantiated by the experience of being with sculptural objects, is externalised in Deren's film through the conjuring of instances of uniquely cinematic illusion. The space between viewing subject and art object is imagined and presented as ominously responsive. The centralised appearance of the hand, reaching out to touch, 
for example, a stack of blocks etched with obscure symbols that proceed to float away, unbidden, suggests that Clark gesturally activates the encountered forms into object life. The film is suffused with symbols of witchcraft; in one scene Clark appears with a pentagram drawn on her forehead, in another she goes to retrieve a cloak from its position on the floor and, through the facility of reverse motion, it floats up into her outstretched hand. In Points of Resistance: Women, Power and Politics in the New York Avant-garde Cinema, 19431971, Lauren Rabinovitz discuses Deren's making of Witch's Cradle with Roberto Matta as an indication of her sympathy with his valorisation of automatist art practices in giving visual form to the realms of the psychical and unseen. "Pure psychic automatism," referred to in Breton's 1924 Le Manifeste du Surréalisme as the definitive mode of Surrealist verbal and written expressions of "the true function of thought," was initially practiced through automatic writing, before expanding into graphic automatism at the instigation of André Masson. ${ }^{21}$ Automatic drawing instituted the hand as the instrumental conduit of the subconscious: by freeing mark-making from the strictures of representation and ration, Surrealist purveyors of the technique believed the practice actively harnessed and revealed something of the artist's psyche. Whilst Matta's particular encouragement and practice of automatism in painting coincided with the Surrealist determination, his interpretations of its psychical ends were divergent. He believed the very activity of automatist practice to be a "live" enactment of patterns of thought, the tools of use and their manipulation rational agents grasping and shaping the irrational flow of the unconscious. ${ }^{22}$ Whilst Deren considered the essential spontaneity of such practices impossible to translate into the act of filmmaking, being as it was the art of recapitulating existing realities, she nonetheless indicates in her writings a belief in cinema's specific facility to conjure the subliminal, which resonates with Matta's thoughts on the function of automatism. In her article, "Cinema as an Art Form," published in New Directions in 1946, Deren describes how the filmic medium, in her words, is "especially equipped" to reveal the "external universe ... as an active, creative force." ${ }^{23}$ In a statement evocative of Witch's Cradle, Deren writes of cinema's unique "capacity for animating the ostensibly inanimate, for re-relating the ostensibly immobile" as a demonstration of the medium's suitability for giving vision to such collectively shared unconscious "forces." Through the animistic characterisation of Surrealist art objects, and emblems of witchcraft, already imbued with automatist and mythic significance, Deren attempted to externalise and articulate a sense of "psychological self-awareness."24

Unable to fully translate into cinema's two-dimensions the weight and volume of the Surrealist gallery's intrusive three-dimensionality, Deren instead configured a uniquely filmic vision of this space, moving up, around and throughout the gallery as the insidious string might have done. Her camera pans vertiginously about the string sculpture; artworks are briefly visible through its geometric contortions. The sense that this static, occluding membrane has the capacity to disrupt spatial comprehension is dizzyingly extended through Deren's mobile camera work. This atmosphere of volatility, a cinematic registration and transposition of the sense of spatial instability affected by Duchamp's string sculpture, images the spaces proposed in the film's fragmented sequences as psychological projections. Deren's concern, as Rabinovitz suggests, to filmically articulate a sense of psychological awareness without, as she writes, "defining it through a 'lack' of rationality,"25 is played out in the existing fragments of Witch's Cradle through the intensely rhythmic manipulation of shots and sequences. Yoking the configurations of string as sculpture and 
as game is a choreographic implication. Deren translates this implication into filmic form, describing a psychologically disruptive space through an integral structural logic.

Both Serra's Hand Catching Lead and Deren's Witch's Cradle cinematically configure the affective relation of body and sculptural form through the staging of choreographic encounter. For Serra, the simple play of hand action in the repetitious execution of anticipatory gesture constitutes a choreographic sequence, and the material, in turn, is afforded a curiously animate quality. In Deren's hands, mechanistic animation and puppet-like artistry configure the space between body and sculptural object as reactive, as strangely contagious: there is the sense that in being touched, the objects touch back, as it were. In staging a series of engagements with the material Duchamp employed in a deliberate dematerialisation of the notion of weight and heft proposed by sculptural objects, Deren extends the transposition of the "actuality" of sculptural form within the "virtuality" of cinematic space. The eventness of tactile encounter between mute object and active subject is precisely what is staged in both Deren and Serra's visual configurations of the relational space between sculptural material and active body. The dynamism implied by this relation is conjured through the filmic medium's unique facility to imbue objects and materials with a previously only imaginable reactive quality.

\section{In the Palace (at $4 \mathrm{am})$}

Deren's attempts to ally camera vision with the subversion of spatial impression, affected by Duchamp's string sculpture, demonstrates how sculptural form might in fact instantiate specifically cinematic registrations of space. The way sculpture might function not as cinematic obstruction but as cinematic device is explored most poignantly in another, more recent treatment of the relation of screen bodies and sculptural frames, Daria Martin's In the Palace of 2000. ${ }^{26}$ In the Palace takes its title from Alberto Giacometti's 1932 work The Palace at 4 am, a small structural scaffold made of wood, glass, wire and string, inhabited by strange forms and suggestions of figuration. Martin constructed a model of Giacometti's sculpture that could inhabit the proportions of a human; when completed it measured over twenty-five feet high and was installed in a disused sports arena. Martin's structural frame becomes the stage set for something approaching a tableaux vivant of dancing bodies stilled in pose or clasped in static embrace, partially dressed in homemade costumes and embellished with reflective materials. For me, the film is oddly reminiscent of the "We're in the Money" number, choreographed by Busby Berkeley, in The Gold Diggers of 1933 —not least because of a nod to Gold Diggers ' coin-like head dressing and scanty costume. There is something in the quality of the camera work and the panning movement around this open structure that at once stages and contains the film's performers that evokes the way those Berkeley spectacles plunge the viewer headlong into beyond-human perspectival dimensions which pose a porosity between the mechanistic and the sensual. As Catherine Wood puts it, in a 2005 article on Martin's practice entitled The One and the Many, "the artist stages a direct level of sensory communion with the viewer which temporarily suspend for the viewing subject the fact that they exist on the worldly plane. This is part of the fantasy of becoming immersed in the work, at least."27

During Martin's film, the camera pans about the scaffold whilst the contained performers mostly remain tremblingly posed, as breathing statues or fleshly idols. Where 
Serra and Deren filmically configure the relation between body and sculptural form as an active encounter choreographed for camera, Martin re-imagines a diminutive sculptural object as a film set, re-appropriating an existing form for the specific purpose of cinematic exhibition. She writes of her fascination with Giacometti's The Palace at $4 a m$ as deriving from the imagined impression of a latent vastness embedded within the object's diminutive proportions: in Martin's words, the "idea that sparked In the Palace was a desire to literally realise my own fantasy to inhabit this small sculpture, to blow it up to human dimensions and to populate it with performers."28 Underscoring the film's conception and realisation is the idea of a passage from compression to expansion and back again. Writing of In the Palace, Martin notes the way in which the performance of filmic projection returns the constructed, "real world" event of filmmaking to the ephemeral presence of cinematic dream. The still photographed instances, embalmed by light upon the celluloid strip, resemble in Martin's imagination a maquette or model, a permanent registration of space and action laboriously constructed and dismantled in the service of the creation of the film properly speaking, which, in projection, expands into visual purpose. ${ }^{29}$ According to Rosalind Krauss, Giacometti made The Palace at 4 am during a time when he believed the sculptural object must be unanchored from his aesthetic calculations, that it must bear neither impression of his touch nor "evidence of his own manipulation. It was to be a projection of desire rather than a product of something painstakingly wrought." ${ }^{30}$ In the Palace and Witch's Cradle can be received as cinematic projections of the oneiric potential of sculptural forms. Both derive from an exploration of the inherent tension between the laborious pragmatisms yoking sculptural and filmic production, and the inevitable expansive estrangement of the work within spectorial space.

Whilst Deren and Martin's films seem at odds with Serra's anti-illusionist, positively perspiratory performance for camera, all three works filmically conjure some degree of the affective force of sculptural encounter. And all three attend to the way film, as a two-dimensional, essentially immaterial projection, can conjure this force through a choreography of action, gesture, or still pose which ultimately transposes the internal, embodied receipt of object and materials into external, almost graphic performances of the body. Redolent in Serra's, Deren's, and Martin's filmic explorations of, perhaps, what happens in the spaces between the receiving, making, performing body, and the structure, material, or object of their receipt, is a sense of the artist's attempt to conjure (to paraphrase Martin) an "ephemeral expansion" of the choreographic labour implied by sculptural production within a qualitatively different dimension of spectatorial space. To close, I will turn to a passage from Stan Brakhage's seminal essay From Metaphors on Vision, which informed my thinking as I attended to these three works so embedded with the weighted sense of film as originating in physical investment: of film as, essentially, manus operandi. On "what reflects from the screen," Brakhage writes:

Believe in it blindly, and it will fool you ... Believe in it eye-wise, and the very comet of its overhead throw from projector to screen will intrigue you so deeply that its fingering play will move integrally with what's reflected, a comet-tail integrity which would lead back finally to the film's creator. ${ }^{31}$ 


\section{References}

Brakhage, Stan. (1963) "From Metaphors on Vision." In The Avant-Garde Film: A Reader of Theory and Criticism. Edited by P. Adams Sitney. New York: Anthology Film Archives, 1987.

Breton, André. "Le Manifeste du Surréalisme." 1924. Accessed April 20, 2011. http://www.tcf.ua.edu/Classes/ Jbutler/T340/SurManifesto/ManifestoOfSurrealism.htm.

Buchloh, Benjamin H.D. "Richard Serra's Early Work: Sculpture between Labour and Spectacle." In Richard Serra: Forty Years, edited by Kynaston McShine and Lynne Cook, 43-60. New York: The Museum of Modern Art, 2007.

Elder, R. Bruce. Harmony and Dissent: Film and Avant-garde Art Movements in the Early Twentieth Century. Waterloo, ON: Wilifrid Laurier Univ. Press, 2008.

Fijalkowski, Krzysztof. "Marcel Duchamp, Surrealist Exhibitions and Restless Space." In The Surreal House, edited by Jane Alison, et. al. New Haven: Yale University Press and the Barbican Art Gallery, 2010.

Gross, Kenneth. "The Madness of Puppets." The Hopkins Review 2, no.2 (Spring 2009): 182-205.

Krauss, Rosalind E. Passages in Modern Sculpture. Cambridge: M.I.T Press. 1994.

Martin, Daria. "Daria Martin in conversation with Yilmaz Dziewior and Beatrix Ruf." Accessed April 20, 2011. http:// www.dariamartin.com/docs/texts.htm\#ruf.

McPherson, Bruce R., ed. Essential Deren: Collected Writings on Film by Maya Deren. Kingston, New York: Documentext, 2005.

"Move: A Digital Archive." Move: Chorepographing You. Hayward Gallery. Accessed Janurary 8, 2011.

Moore, Rachel O. Savage Theory: Cinema as Modern Magic. Durham: Duke University Press, 2000.

Rabinovitz, Lauren. Points of Resistance: Women, Power and Politics in the New York Avant-garde Cinema, 1943-1971. Chicago: University of Illinois Press, 1991.

"Roberto Matta," by Martica Sawin. Latin American Masters. Accessed April 20, 2011. http://latinamericanmasters. com/english/artist_matta_essay.html.

Turim, Maureen. "The Ethics of Form: Structure and Gender in Maya Deren's Challenge to Cinema." In Maya Deren and the American Avant-Garde, edited by Bill Nichols, 77-102. Berkley: University of California Press, 2001.

Wood, Catherine. "The One and the Many." Daria Martin. Accessed April 20, 2011.

\section{Notes}

1. Fernand Léger, "A New Realism—The Object (Its Plastic and Cinematographic Value)," from Little Review 11, no. 2 (1926). Quoted in R. Bruce Elder, Harmony and Dissent, 165.

2. Both Hand Catching Lead and Witch's Cradle were included in a Lux touring program, entitled Describing Form, curated by Lucy Reynolds. Describing Form premiered at the Henry Moore Institute and Tate in 2005, before touring UK venues. The program included Deren's Witch's Cradle and Serra's Hand Catching Lead, alongside works by Daria Martin, Marie Menken, and Hannah Wilke, among others, in a programme that sought to explore how the weight and space implied by sculptural form has been filmically described.

3. Rosalind Krauss, Passages in Modern Sculpture, 243.

4. Ibid., 244.

5. Benjamin H.D Buchloh, "Richard Serra's Early Work," 57.

6. Krauss, 244.

7. Ibid.

8. Rachel O. Moore, Savage Theory, 73.

9. Ibid.

10. Kenneth Gross, "The Madness of Puppets,"183.

11. Ibid, 182.

12. Maureen Turim, "The Ethics of Form," 8.

13. Ibid. 
14. Maya Deren, "Theme and Form: Thematic Statement," from Film Culture, 39 (Winter 1965). Quoted in Turim, "The Ethics of Form," 88.

15. See Deren, "Choreography for Camera."

16. Maya Deren, "Ritual in Transfigured Time," from Dance Magazine, December 1946. In Bruce R. McPherson, Essential Deren ), 225.

17. Turim, "The Ethics of Form," 85.

18. Maya Deren, "Choreography for Camera," from Dance Magazine, October 1945. In Essential Deren, 224.

19. Maya Deren, "Creating Movies with a New Dimension: Time," from Popular Photography, December 1946. In Essential Deren, 133.

20. Krzysztof Fijalkowski, "Marcel Duchamp, Surrealist Exhibitions and Restless Space," 68.

21. André Breton, "Le Manifeste du Surréalisme."

22. "Roberto Matta."

23. Maya Deren, "Cinema as an Art Form," from issue 9 of the 1946 NewDirections. In McPherson, 32.

24. Lauren Rabinovitz, Points of Resistance, 69.

25. Ibid

26. Daria Martin, In the Palace and Birds (2001) are available at "Move: A Digital Archive."

27. Wood, Catherine. "The One and the Many."

28. Daria Martin, "Daria Martin in conversation with Yilmaz Dziewior and Beatrix Ruf."

29. Ibid

30. Krauss, "Passages in Modern Sculpture," 111 (emphasis mine).

31. Brakhage, Stan. "From Metaphors on Vision" (1963). In The Avant-Garde Film: A Reader of Theory and Criticism, edited by P. Adams Sitney. New York: Anthology Film Archives, 1987. 